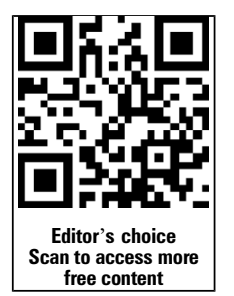

free content

\title{
Hypoglycaemia and hyperglycaemia are associated with unfavourable outcome in infants with hypoxic ischaemic encephalopathy: a post hoc analysis of the CoolCap Study
}

\author{
Sudeepta K Basu, ${ }^{1,2}$ Jeffrey R Kaiser, ${ }^{1}$ Danielle Guffey, ${ }^{3}$ Charles G Minard, ${ }^{3}$ \\ Ronnie Guillet, ${ }^{4}$ Alistair J Gunn, ${ }^{5}$ for the CoolCap Study Group
}

${ }^{1}$ Baylor College of Medicine, Houston, Texas, USA ${ }^{2}$ Children's National Medical Center, Washington, DC, USA ${ }^{3}$ Dan L. Duncan Institute for Clinical and Translational Research, Baylor College of Medicine, Houston, Texas, USA ${ }^{4}$ University of Rochester Medical Center, Rochester, Texas, New York, USA ${ }^{5}$ University of Auckland, Auckland, New Zealand

Correspondence to Dr Jeffrey R Kaiser, Department of Pediatrics and Obstetrics and Gynecology, Baylor College of Medicine, 6621 Fannin Street, MC: WT 6-104, Houston, TX 77030, USA; jrkaiser@texaschildrens.org

Received 4 April 2015 Revised 28 July 2015 Accepted 29 July 2015 Published Online First 17 August 2015

\section{ABSTRACT}

Objective To investigate the association of neonatal hypoglycaemia and hyperglycaemia with outcomes in infants with hypoxic ischaemic encephalopathy (HIE).

Design Post hoc analysis of the CoolCap Study.

Setting 25 perinatal centres in the UK, the USA and New Zealand during 1999-2002.

Patients 234 infants at $\geq 36$ weeks' gestation with moderate-to-severe HIE enrolled in the CoolCap Study. $214(91 \%)$ infants had documented plasma glucose and follow-up outcome data.

Intervention Infants were randomised to head cooling for $72 \mathrm{~h}$ starting within $6 \mathrm{~h}$ of birth, or standard care. Plasma glucose levels were measured at predetermined time intervals after randomisation.

Main outcome measure The unfavourable primary outcome of the study was death and/or severe neurodevelopmental disability at 18 months. Hypoglycaemia ( $\leq 40 \mathrm{mg} / \mathrm{dL}, \leq 2.2 \mathrm{mmol} / \mathrm{L}$ ) and hyperglycaemia ( $>150 \mathrm{mg} / \mathrm{dL},>8.3 \mathrm{mmol} / \mathrm{L}$ ) during the first $12 \mathrm{~h}$ after randomisation were investigated for univariable and multivariable associations with unfavourable primary outcome.

Results $121(57 \%)$ infants had abnormal plasma glucose values within $12 \mathrm{~h}$ of randomisation. Unfavourable outcome was observed in 126 (60\%) infants and was more common among subjects with hypoglycaemia $(81 \%, p=0.004)$, hyperglycaemia $(67 \%, p=0.01)$ and any glucose derangement within the first $12 \mathrm{~h}(67 \%, \mathrm{p}=0.002)$ compared with normoglycaemic infants (48\%) in univariable analysis. These associations remained significant after adjusting for birth weight, Apgar score, pH, Sarnat stage and hypothermia therapy.

Conclusions Both hypoglycaemia and hyperglycaemia in infants with moderate-to-severe HIE were independently associated with unfavourable outcome. Future studies are needed to investigate the prognostic significance of these associations and their role as biomarkers of brain injury.

Trial registration number (ClinicalTrials.gov NCT00383305).

\section{CrossMark}

To cite: Basu SK, Kaiser JR, Guffey D, et al. Arch Dis Child Fetal Neonatal Ed 2016;101:F149-F155.

\section{INTRODUCTION}

Hypoxic ischaemic encephalopathy (HIE) is one of the most serious perinatal complications and remains associated with a high risk of death or longterm neurodisability. Despite advances in obstetric care, moderate-to-severe HIE affects 1.5-3 per

\section{What is already known on this topic}

- Postnatal deranged glucose homeostasis is common in infants with hypoxic ischaemic encephalopathy; the relationship with long-term outcome is unclear.

- Previous studies have found univariable associations with hypoglycaemia and hyperglycaemia and long-term outcome, but not after multivariable analysis.

\section{What this study adds}

- This study reports that hypoglycaemia and hyperglycaemia during the early postnatal period in infants with hypoxic ischaemic encephalopathy are associated with unfavourable outcome at 18 months.

- These associations remained significant after adjusting for birth weight, Apgar score, $\mathrm{pH}$, Sarnat stage and hypothermia therapy.

- The odds of an unfavourable outcome were higher in infants with hypoglycaemia (OR 6.2), hyperglycaemia (OR 2.7) and any glucose derangement (OR 3) compared with normoglycaemic infants.

1000 term live births in developed countries. ${ }^{1}{ }^{2}$ There is now compelling evidence that mild hypothermia induced within $6 \mathrm{~h}$ after resuscitation can improve long-term survival without disability. ${ }^{3}$ However, many infants still die or survive with disability, and recent data suggest that longer or deeper cooling did not reduce death at hospital discharge. ${ }^{4}$ Thus, it is important to investigate whether other factors may help to further optimise care.

Glucose is the primary substrate for energy metabolism in the newborn brain, and deranged metabolism may contribute to neuronal injury. ${ }^{5} 6$ At birth, the continuous transplacental infusion of glucose ends; normal postnatal glucose homeostasis then depends on hepatic glycogen reserves, hormonal regulation and external provision of enteral or parenteral substrate. Hypoglycaemia and hyperglycaemia occur frequently in infants with HIE, likely 
due to the profound metabolic and hormonal disturbances. ${ }^{7-9}$ Their effect on long-term outcome is unclear. Although one study found that early hypoglycaemia was a risk factor for short-term perinatal brain injury in newborns with HIE, ${ }^{9}$ others did not find a relationship between early hypoglycaemia and adverse neurodevelopmental outcome at 24 months age after adjusting for HIE severity. ${ }^{7}$ Two retrospective studies reported conflicting results on the association between early hyperglycaemia and unfavourable outcome in infants with HIE. ${ }^{7} 10$ Thus, there is no conclusive evidence that deranged glucose metabolism in infants with HIE is independently associated with unfavourable long-term neurological outcome.

Animal studies support the potential for neuronal injury from deranged glucose homeostasis in the setting of asphyxia. Induced hypoglycaemia decreased the cerebrovascular response to hypoxia, increased cerebral superoxide production and aspartate levels in the brain extracellular space, and promoted neuronal necrosis. ${ }^{11-14}$ Hyperglycaemia before acute hypoxia ischaemia or ischaemia markedly increased brain injury in animal models. ${ }^{15-17}$

We therefore examined the hypothesis that early transient or recurrent hypoglycaemia $(\leq 40 \mathrm{mg} / \mathrm{dL}, \leq 2.2 \mathrm{mmol} / \mathrm{L})^{8}$ and hyperglycaemia $(>150 \mathrm{mg} / \mathrm{dL}, 8.3 \mathrm{mmol} / \mathrm{L})^{7}$ in infants with moderate-to-severe HIE would be independently associated with death or severe neurodevelopmental disability (primary unfavourable outcome) in a post hoc analysis from the CoolCap Study. ${ }^{18}$

\section{METHODS}

Subjects

The CoolCap Study was a multicentre randomised controlled study of selective head cooling and mild systemic hypothermia for the treatment of perinatal moderate-to-severe HIE in 234 infants at $\geq 36$ weeks' gestation enrolled between 1999 and $2002 .{ }^{18}$ This study was performed in 25 perinatal centres using a trial design registered with the US Food and Drug Administration under the Investigational Device Exemption/ Premarket Approval programme. Study subjects were randomised to head cooling for $72 \mathrm{~h}$ starting within $6 \mathrm{~h}$ of birth, with rectal temperature maintained at $34.5 \pm 0.5^{\circ} \mathrm{C}$, followed by rewarming over $4 \mathrm{~h}$ or standard care at $37.0 \pm 0.5^{\circ} \mathrm{C}$. The primary unfavourable study outcome was death or severe disability (ie, gross motor function classification system level 3-5, Bayley scales of infant development II mental developmental index $<70$ or bilateral cortical visual impairment) at 18 months. CoolCap Study subjects were eligible $(n=215,92 \%)$ for the current analysis if they completed follow-up evaluations, and plasma glucose values were available in the database (figure 1 ).

Plasma glucose levels, at predefined time points $(0,4,8,12$, 24,48 and $72 \mathrm{~h}$ from randomisation), were analysed to investigate the association between derangements in glucose homeostasis with the primary unfavourable outcome. Demographic and perinatal data included birth weight, gestational age, gender, race, mode of delivery, pregnancy complications and Apgar scores at 1 and $5 \mathrm{~min}$. Other clinical data were first $\mathrm{pH}$,
Figure 1 Flow of infants through the trial.
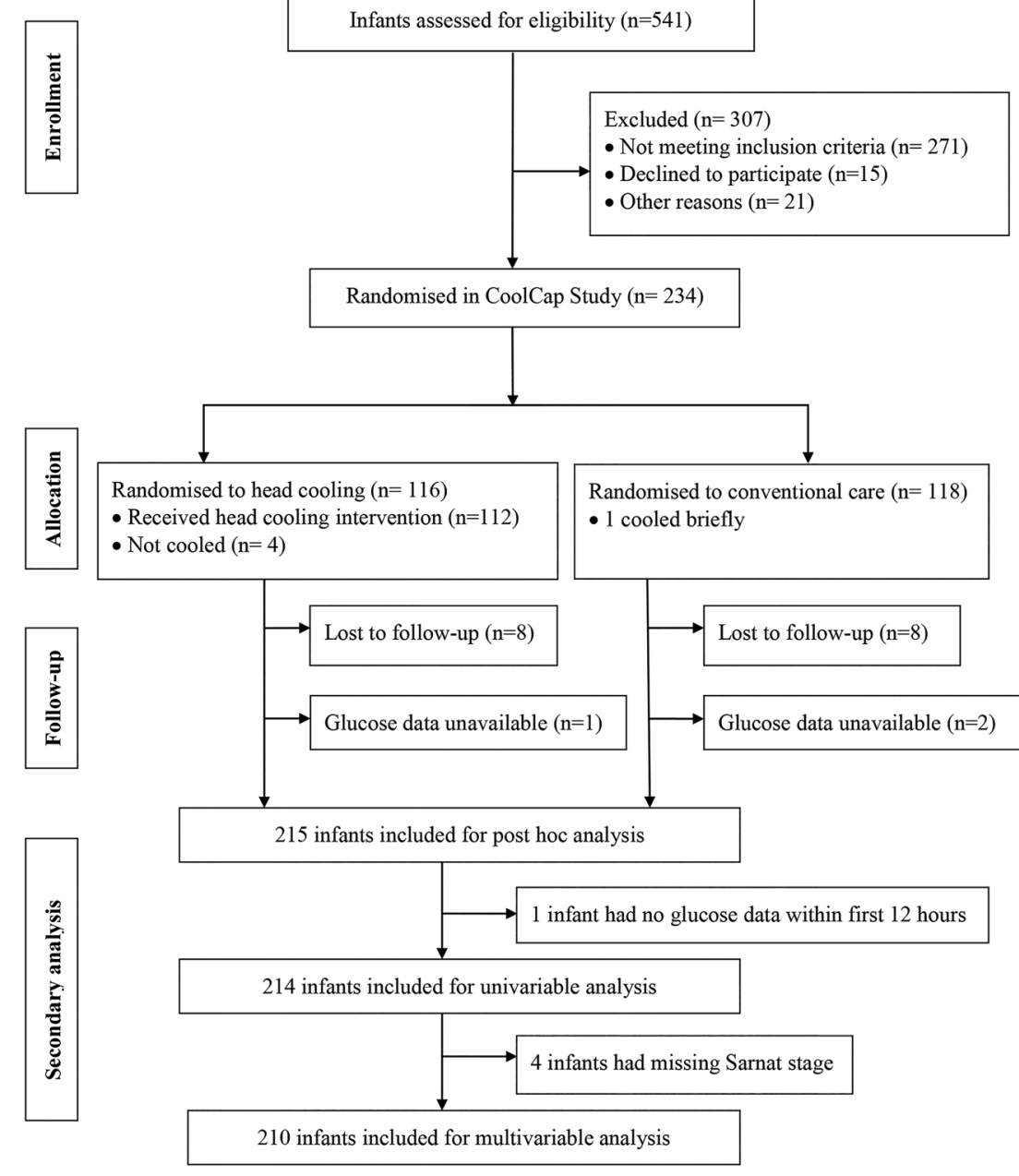
modified Sarnat and Sarnat stage at randomisation, ${ }^{19}$ age at study randomisation, treatment with hypothermia or conventional therapy, presence of seizures, death and Bayley Scales of Infant Development II mental developmental index scores at 18 months. Infants were randomised at a median of 4.8 (IQR 4.1-5.3) hours after birth in the CoolCap Study. For the purposes of this study, time points refer to the period after randomisation, and not hours of life. ${ }^{18}$

\section{Statistical analysis}

Demographic, obstetric and neonatal parameters were stratified by primary outcome (favourable vs unfavourable) and compared using $\chi^{2}$ test, Fisher's exact test, t test or Wilcoxon rank-sum test as appropriate. Episodes of hypoglycaemia, normoglycaemia and hyperglycaemia as single or recurrent occurrences during the first $12 \mathrm{~h}$ were documented for all subjects. Multiple logistic regression models were built to investigate the association between deranged glucose values and an unfavourable outcome. Covariates with $\mathrm{p}<0.1$ from univariable analysis were included a priori in the multiple regression models. Statistical significance for the final models was assessed at the 0.05 level, and no adjustment was made for multiple hypothesis testing in this exploratory analysis. Statistical analysis was conducted using Stata V.12.1 (StataCorp LP, College Station, Texas, USA).

\section{RESULTS}

Study demographic data stratified by 18 -month outcome are shown in table 1 . Infants with an unfavourable outcome were generally larger, less likely to have been cooled, had more severe versus moderate HIE, had lower 5 min Apgar scores and were more acidotic. Incidentally, only four study infants had septicaemia. Therefore, meaningful statistical associations between septicaemia and glucose derangements and outcome could not be established.

\section{Early postnatal glucose profile}

The time period after randomisation that was most informative for predicting an unfavourable outcome was during the first $12 \mathrm{~h}$. At the time of randomisation, of infants with recorded plasma glucose levels, 7\% (15/205) were hypoglycaemic and $34 \%(70 / 205)$ were hyperglycaemic. During the first $12 \mathrm{~h}, 13 \%$ $(27 / 214)$ of infants had at least one episode of hypoglycaemia, $48 \%(102 / 214)$ had at least one episode of hyperglycaemia and $57 \%$ (121/214) had $\geq 1$ episode(s) of hypoglycaemia or hyperglycaemia (table 2 ). Of 207 infants who had $\geq 1$ glucose values obtained during the first $12 \mathrm{~h}, 30 \%$ had $\geq 2$ deranged values and $8 \%$ had both hypoglycaemia and hyperglycaemia. The incidence of hypoglycaemia and hyperglycaemia progressively decreased over time during the $72 \mathrm{~h}$ study period. Later $(>12 \mathrm{~h}$ after randomisation) glucose derangements were not associated with outcome.

\section{Univariable analysis}

Relationship between deranged glucose at individual time points $(0,4,8$ and $12 \mathrm{~h})$ and unfavourable outcome

At the time of randomisation, $9 \%$ and $41 \%$ of infants with unfavourable outcome had hypoglycaemia or hyperglycaemia, respectively, compared with $5 \%$ and $24 \%$ of infants with favourable outcome $(p=0.011)$. Derangements of glucose at 4 and $8 \mathrm{~h}$ were significantly more common in infants with unfavourable outcome (figure 2).

\section{Relationship between hypoglycaemia within $12 \mathrm{~h}$ and} unfavourable outcome

Infants with at least one episode of hypoglycaemia during the first $12 \mathrm{~h}$ were more likely to have an unfavourable outcome. Among the 27 infants with hypoglycaemia within $12 \mathrm{~h}, 22$ $(81 \%)$ had an unfavourable outcome at 18 months of age compared with only $48 \%$ of infants with normoglycaemia $(p=0.004$, table 2$)$.

\section{Relationship between hyperglycaemia within $12 \mathrm{~h}$ and} unfavourable outcome

Infants with at least one episode of hyperglycaemia during the first $12 \mathrm{~h}$ were also more likely to have an unfavourable outcome. Among the 102 infants with hyperglycaemia within $12 \mathrm{~h}, 68(67 \%)$ had an unfavourable outcome, significantly higher than normoglycaemic infants $(p=0.01$, table 2$)$.

\section{Relationship between recurrent glucose derangements and} unfavourable outcome

Recurrent hypoglycaemia ( $>1$ episode within the first $12 \mathrm{~h}$ ) was present in only $11(5 \%)$ of the infants; $82 \%$ of these infants had an unfavourable outcome compared with $48 \%$ among normoglycaemic infants $(p=0.052$, table 2$)$. Recurrent hyperglycaemia (>1 episode within the first $12 \mathrm{~h}$ ) was noted in $19 \%(39 / 207)$ of the infants; $77 \%$ of these infants had an unfavourable outcome compared with $48 \%$ among infants with normoglycaemia $(p=0.002$, table 2$)$.

Table 1 Baseline characteristics of infants from the CoolCap Study

\begin{tabular}{|c|c|c|c|c|}
\hline $\begin{array}{l}\text { Characteristics } \\
\text { n (\%) }\end{array}$ & $\begin{array}{l}\text { All subjects } \\
215\end{array}$ & $\begin{array}{l}\text { Favourable outcome } \\
85(39.5 \%)\end{array}$ & $\begin{array}{l}\text { Unfavourable outcome } \\
130(60.5 \%)\end{array}$ & $p$ Value \\
\hline Birth weight, mean (SD), g & $3445(646)$ & $3295(625)$ & $3544(643)$ & 0.006 \\
\hline Hypothermia treatment, n (\%) & $107(50 \%)$ & $49(58 \%)$ & $58(45 \%)$ & 0.06 \\
\hline Severe HIE, n (\%) & $74(35 \%)$ & $15(18 \%)$ & $59(46 \%)$ & $<0.001$ \\
\hline Male, n (\%) & $114(53 \%)$ & $44(52 \%)$ & $70(54 \%)$ & 0.77 \\
\hline Caesarean delivery, n (\%) & $149(69 \%)$ & $64(75 \%)$ & $85(65 \%)$ & 0.12 \\
\hline Delivery complications*, n (\%) & $174(81 \%)$ & $66(78 \%)$ & $108(83 \%)$ & 0.32 \\
\hline White race, $\mathrm{n}(\%)$ & $136(63 \%)$ & $54(64 \%)$ & $82(63 \%)$ & 0.95 \\
\hline Apgar 5 min, median(IQR) & $3(0-4)$ & $3(1-4)$ & $2(0-4)$ & 0.02 \\
\hline $\mathrm{pH}$, mean (SD) & $6.88(0.22)$ & $6.95(0.22)$ & $6.83(0.21)$ & $<0.001$ \\
\hline
\end{tabular}


Table 2 Univariable analysis of association of deranged glucose parameters with unfavourable outcome

\begin{tabular}{|c|c|c|c|c|c|}
\hline $\begin{array}{l}\text { Deranged glucose parameter within first } 12 \mathrm{~h} \text { after } \\
\text { randomisation }\end{array}$ & $\mathbf{n}$ & $\begin{array}{l}\text { Infants with } \\
\text { deranged } \\
\text { glucose } \mathrm{n}(\%)\end{array}$ & $\begin{array}{l}\text { Unfavourable outcome } \\
\text { among infants with } \\
\text { deranged glucose (\%) }\end{array}$ & $\begin{array}{l}\text { Unfavourable outcome } \\
\text { among normoglycaemic } \\
\text { infants }(\%)\end{array}$ & p Value \\
\hline Hypoglycaemia & $214^{*}$ & $27(13)$ & $22 / 27(81)$ & $45 / 93(48)$ & 0.004 \\
\hline Hyperglycaemia & 214 & $102(48)$ & $68 / 102(67)$ & $45 / 93(48)$ & 0.01 \\
\hline Hypoglycaemia and/or hyperglycaemia & 214 & $121(57)$ & $84 / 121(69)$ & $45 / 93(48)$ & 0.002 \\
\hline Both hypoglycaemia and hyperglycaemia & $207+$ & $8(4)$ & $6 / 8(75)$ & $42 / 88(48)$ & 0.27 \\
\hline Recurrent hypoglycaemia & 207 & $11(5)$ & $9 / 11(82)$ & $42 / 88(48)$ & 0.052 \\
\hline Recurrent hyperglycaemia & 207 & $39(19)$ & $30 / 39(77)$ & $42 / 88(48)$ & 0.002 \\
\hline Recurrent hyperglycaemia or hypoglycaemia & 207 & $63(30)$ & $50 / 63(79)$ & $42 / 88(48)$ & $<0.001$ \\
\hline
\end{tabular}

\section{Multivariable analysis}

Glucose derangements were significant independent predictors of unfavourable outcome after adjusting for birth weight, hypothermia therapy, Sarnat stage (III vs II), Apgar score at 5 min and first $\mathrm{pH}$ (table 3). The odds of an unfavourable outcome were 6.2 times greater among infants with at least one episode of hypoglycaemia, 2.7 times greater among infants with at least one episode of hyperglycaemia and three times greater in those with at least one episode of any glucose derangement (hypoglycaemia or hyperglycaemia) within the first $12 \mathrm{~h}$ compared with normoglycaemic infants. Infants with recurrent hypoglycaemia (5\% of infants, OR 2.1, 95\% CI 0.52 to 8.3 ) and recurrent hyperglycaemia (19\% of infants, OR 4.5 , 95\% CI 1.7 to 12.0 ) had an increased incidence of unfavourable outcome $(82 \%$ and $77 \%$, respectively), although the number of newborns with recurrent glucose abnormalities was small.

\section{DISCUSSION}

This study reports systematically collected and analysed evidence that early hypoglycaemia, hyperglycaemia and indeed, any glucose derangement during the early postnatal period, in infants with moderate-to-severe HIE are independently associated with an unfavourable outcome at 18 months. It is not possible to determine from this exploratory analysis whether this association with deranged glucose metabolism is causal. Hypoglycaemia reflects at least in part depletion of hepatic glycogen reserves during severe asphyxia, and hepatic injury. ${ }^{20}$ Similarly, hyperglycaemia may be a proxy for severity of brain injury, as severely damaged tissues show reduced net metabolism, ${ }^{21}$ or due to prolonged elevation of stress hormones after asphyxia. $^{22}$ Consistent with the present study, neonatal hyperglycaemia is common in preterm and sick infants. ${ }^{23}$ The specific mechanisms are likely multifactorial, related to impaired insulin
Figure 2 Distribution of glucose values at each time point during the first $12 \mathrm{~h}$ stratified by favourable versus unfavourable primary outcome. Y-axis depicts percentage of subjects with hyperglycaemia, normoglycaemia and hypoglycaemia at each time point. The $\mathrm{n}$ is reported in the columns.

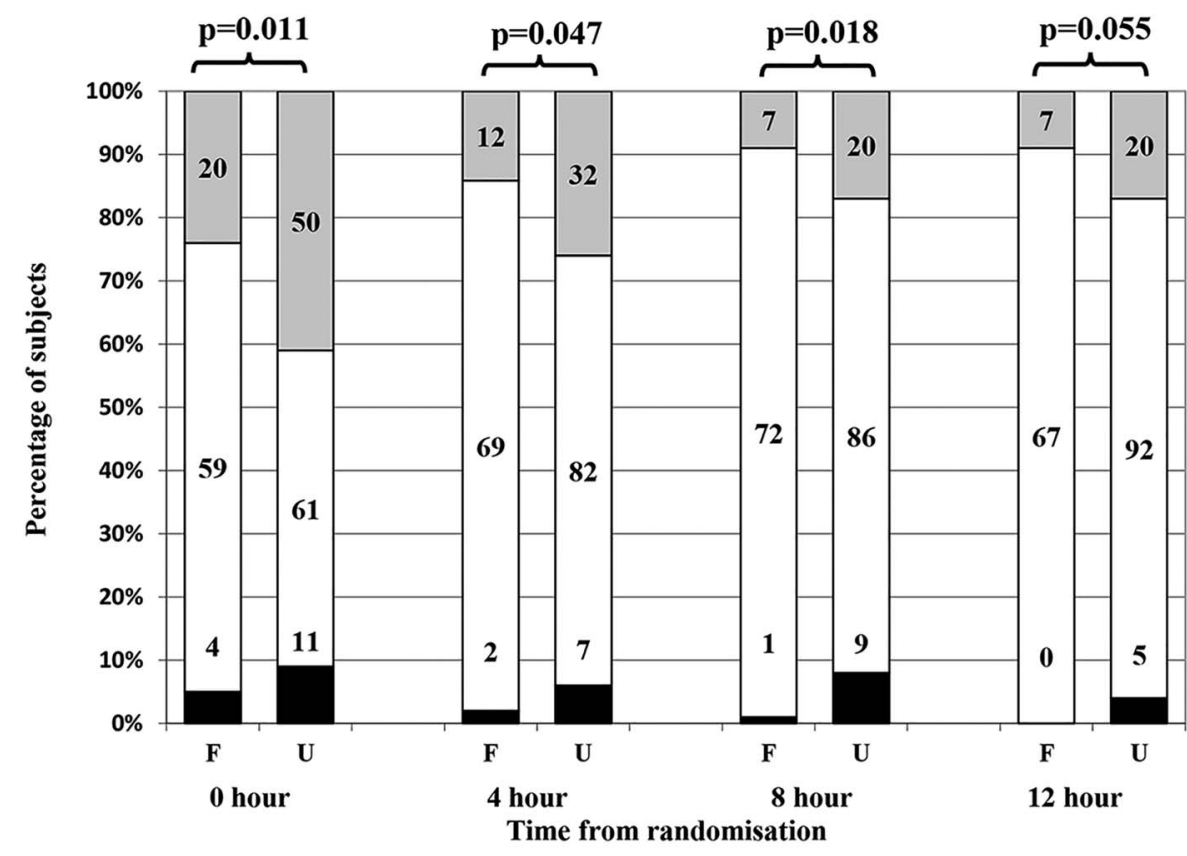

$F=$ Favourable outcome U= Unfavourable outcome

- Hypoglycaemia $\square$ Hyperglycaemia 
Table 3 Multivariable analysis of association of deranged glucose parameters with unfavourable outcome

\begin{tabular}{|c|c|c|c|}
\hline \multirow[b]{2}{*}{$\begin{array}{l}\text { Deranged glucose parameter } \\
\text { within } 12 \mathrm{~h} \text { of randomisation }\end{array}$} & \multicolumn{3}{|c|}{ Unfavourable outcome } \\
\hline & $\begin{array}{l}\text { Adjusted } \\
\text { OR }\end{array}$ & $95 \% \mathrm{Cl}$ & $\begin{array}{l}p \\
\text { Value }\end{array}$ \\
\hline Hypoglycaemia & 6.2 & 1.4 to 27.3 & 0.016 \\
\hline Hyperglycaemia & 2.7 & 1.5 to 4.9 & 0.001 \\
\hline Hypoglycaemia or hyperglycaemia & 3.0 & 1.6 to 5.8 & 0.001 \\
\hline Both hypoglycaemia and hyperglycaemia & 3.5 & 0.99 to 12.1 & 0.052 \\
\hline Recurrent hypoglycaemia & 2.1 & 0.52 to 8.3 & 0.304 \\
\hline Recurrent hyperglycaemia & 4.5 & 1.7 to 12.0 & 0.003 \\
\hline $\begin{array}{l}\text { Recurrent hypoglycaemia and/or } \\
\text { hyperglycaemia }\end{array}$ & 2.5 & 1.4 to 4.2 & 0.001 \\
\hline $\begin{array}{l}\text { Recurrent hyperglycaemia and/or } \\
\text { hypoglycaemia }\end{array}$ & 5.0 & 1.9 to 13.5 & 0.001 \\
\hline
\end{tabular}

Statistical model adjusted for birth weight, hypothermia therapy, Sarnat stage (III vs II), Apgar score at $5 \mathrm{~min}$ and first pH.

response, excessive hepatic glucose production, sepsis and stress-induced increase in counter-regulatory hormones. ${ }^{24} 25$

Neonatal hypoglycaemia has been investigated for its association with unfavourable neurodevelopmental and academic outcome in term and preterm infants. ${ }^{26-28}$ Although the definition of neonatal hypoglycaemia has been highly controversial, the American Academy of Pediatrics currently recommends early identification of the at-risk infant and institution of prophylactic measures to prevent neonatal hypoglycaemia. ${ }^{29}$ However, only a few studies have examined the influence of early hypoglycaemia in infants with HIE on long-term neurodevelopmental outcome. ${ }^{7-9} 30$ One study of 60 infants with HIE showed a significant association between hypoglycaemia and HIE severity, but did not evaluate longer-term outcomes. ${ }^{9}$ In another study of 185 term infants with fetal acidemia, investigators observed that hypoglycaemia was associated with early abnormal neurological outcome (ie, severe HIE and death, moderate-to-severe HIE and seizures). However, this study did not evaluate outcome after hospital discharge. ${ }^{8}$ In another study, although early hypoglycaemia was associated with adverse outcome at 24 months in 52 term infants with HIE in univariate analysis, hypoglycaemia was not a significant predictor after adjustment for severity of HIE. ${ }^{7}$ None of the infants included in the above studies received therapeutic hypothermia. ${ }^{7-9}$ More recently, in a prospective cohort study of 94 term infants at risk for neonatal encephalopathy, of whom $12 \%$ were treated with hypothermia, investigators reported that hypoglycaemia was associated with worse motor and cognitive outcome at 1 year. ${ }^{30}$

There are very limited data describing hyperglycaemia in neonates outside of sick extremely premature infants or due to iatrogenic causes, and its relationship with outcome is not clearly understood. $^{23}$ A retrospective analysis of 52 term infants with HIE found that hyperglycaemia occurred frequently but was not associated with an unfavourable outcome. ${ }^{7}$ Conversely, in a smaller retrospective study, early hyperglycaemia (in univariate analysis only) in infants with HIE was associated with long-term gross motor deficits. ${ }^{10}$ We previously reported that mild hypothermia was associated with an early increase in mean plasma glucose levels. ${ }^{18}$ The present study demonstrates that hypoglycaemia as well as hyperglycaemia during the first $12 \mathrm{~h}$ were associated with an unfavourable outcome at 18 months age, independent of severity of HIE and cooling therapy.

Our findings are supported by pathophysiological observations of deranged energy metabolism from animal models of asphyxia. During asphyxia, anaerobic glycolysis in the brain increased less in hypoglycaemic than normoglycaemic newborn dogs, resulting in more rapid exhaustion of high-energy phosphate reserves (phosphocreatine and ATP). ${ }^{31}$ Hypoglycaemia selectively impairs cerebrovascular autoregulation by suppressing adenosine-mediated cerebrovascular dilation in newborn piglets. $^{11}$

Hyperglycaemia during hypoxia ischaemia or ischaemia increases subsequent brain injury in piglets, fetal sheep and adult rodents. ${ }^{15-17}$ In fetal sheep, hyperglycaemia during asphyxia reduces cerebral oxygen consumption and increases acidosis. ${ }^{32}$ In contrast, post-insult treatment has had variable results. Some studies, in neonatal rodents, piglets and fetal sheep, have suggested no effect. ${ }^{16} 33{ }^{34}$ In contrast, in newborn piglets, hyperglycaemia impaired recovery of brain cell membrane function and energy metabolism. ${ }^{35}$ Further, hyperglycaemia following maternal dexamethasone treatment after asphyxia in fetal sheep was associated with increased brain injury. ${ }^{36}$ It may be that these contrasting results reflect more adverse effects of greater durations of hyperglycaemia or a deleterious effect of the combination of high levels of glucocorticoids with hyperglycaemia. Finally, it is interesting to note that although glucose infusion after asphyxial cardiac arrest per se did not increase injury in adult rats, a combined glucose and insulin infusion markedly reduced histological brain injury. ${ }^{37}$

${ }^{18}$ F-fluorodeoxyglucose positron emission tomography imaging in infants with HIE has found deranged glucose metabolism in affected brain areas. ${ }^{38}$ Total and regional cerebral glucose metabolic rates measured during the subacute period after perinatal asphyxia in term infants were inversely correlated with HIE severity and short-term outcome. ${ }^{39}$ MRI on day 3 in infants with HIE and hypoglycaemia suggests that hypoglycaemic brain injury was superimposed on patterns of hypoxic ischaemic brain injury. ${ }^{40}$

Several limitations of the present study should be taken into consideration. The analysis was post hoc, and so it is important that the findings are confirmed in prospective studies. We do not have glucose values between the predefined time points or continuous values and so may have underestimated the true incidence and duration of hypoglycaemia and hyperglycaemia. However, the study is strengthened by the regular and systematic determination of glucose levels at discrete time points that were not dependent on clinical decisions as in other retrospective studies. Glucose infusion rates from parenteral nutrition and intravenous fluids were not standardised across subjects, and this information was not available for the present exploratory analysis. Further, there was no information regarding treatment thresholds or interventions used, as this was not pre-specified by the original study, whether interventions were provided, or how interventions to achieve normoglycaemia influenced outcome. Thus, the trend of glucose levels towards normoglycaemia over time could represent a response to treatment, or more likely, the natural history of improving glucose homeostasis in infants with moderate-to-severe HIE. We also do not have information on the source (arterial, venous or capillary) of blood samples, and whether different sources of glucose levels could affect interpretation. Future prospective studies are needed to further investigate these associations.

\section{CONCLUSIONS}

Deranged glucose homeostasis was common during the first $12 \mathrm{~h}$ after randomisation in infants with moderate-to-severe HIE. Both hypoglycaemia and hyperglycaemia were associated with unfavourable outcome at 18 months of age, independent 
of HIE severity and hypothermia treatment. Future studies are needed to investigate whether early deranged glucose metabolism in infants with HIE is a biomarker for neuronal injury, has prognostic significance and aggravates further brain injury.

Acknowledgements We thank the many technicians, nurses, physicians and scientists in the participant sites who contributed to the development and implementation of the CoolCap Study, and the parents who consented to enrolment of their infants in the trial who trusted in us under conditions of great stress and anxiety. We thank the many charities and research funding agencies who supported the preliminary research necessary for the study. The original study was designed by and was the responsibility of the Scientific Advisory Committee (SAC), who had full access to the trial data, and after reading and editing this manuscript, approved the final draft for submission.

Collaborators The CoolCap Study Group-Executive Committee: P.D. Gluckman (chair, co-principal investigator), J.S. Wyatt (co-principal investigator), and A.J. Gunn (Scientific Officer). SAC: J.S. Wyatt (chair), R. Ballard, A.D. Edwards, D.M. Ferriero, P.D. Gluckman, A.J. Gunn, R. Polin, C. Robertson, and A. Whitelaw. Data Safety Committee: R. Soll (chair), M. Bracken, C. Palmer, M. Heymann, and A.Wilkinson. Hospital Investigators: J.R. Kaiser (Arkansas Children's Hospital, 11 patients), M. Battin, D. Armstrong (University of Auckland-National Women's Hospital, NZ, 11 patients), J. Khan (Children's Memorial Hospital and Prentice Women's Hospital of Northwestern Memorial Hospital, 3 patients), T. Raju (University of Illinois at Chicago, 1 patient), R. Polin, R. Sahni, U. Sanocka (Children's Hospital of New York-Presbyterian, Columbia University, 18 patients), A. Rosenberg, J. Paisley (Children's Hospital of Denver, 23 patients), R. Goldberg, M. Cotton (Duke University, 14 patients), A. Peliowski, E. Phillipos (Royal Alexandra Hospital/ University of Alberta Hospital, 20 patients), D. Azzopardi, A.D. Edwards (Hammersmith Hospital, London, UK, 1 patient), F. Northington (Johns Hopkins University, 2 patients), J. Barks, S. Donn (University of Michigan-Mott Children's Hospital, 12 patients), B. Couser (Children's Hospital and Clinics of Minneapolis, 16 patients), D. Durand (Children's Hospital and Research Center at Oakland, 8 patients), K. Sekar (Children's Hospital of Oklahoma, 4 patients), D. Davis, M. Blayney (Children's Hospital of Eastern Ontario/The Ottawa Hospital, 1 patient), S. Adeniyi-Jones (Al Dupont Children's Hospital at Thomas Jefferson University, 6 patients), T. Yanowitz (Magee Women's Hospital/Children's Hospital of Pittsburgh, 10 patients), R. Guillet, N. Laroia (Golisano Children's Hospital at Strong, 10 patients), N. Finer, F. Mannino (University of California San Diego Medical Center (Hillcrest), 8 patients), J. Partridge (University of California San Francisco Children's Hospital, 2 patients), D. Davidson (Schneider Children's Hospital, 14 patients), A. Whitelaw (Southmead Hospital. Bristol, UK, 13 patients), M. Thoresen (St. Michael's Hospital, Bristol, UK, 8 patients), J.S. Wyatt, F. O'Brien (University College Hospital, London, UK, 4 patients), B. Walsh (Vanderbilt Children's Hospital, 13 patients), J. Perciaccante, and M. O'Shea (Wake Forest University Baptist Medical Center, 1 patient). Manufacturer's Representatives: J. Jones, T. Weiler, J. Mullane, D. Hammond, and J. Parnell (Olympic Medical, Seattle, Washington, USA).

Contributors SKB: conceptualised and designed the study, drafted the initial manuscript and approved the final manuscript as submitted. JRK, RG and AJG: conceptualised and designed the study, supervised data analysis and interpretation, reviewed and revised the manuscript, and approved the final manuscript as submitted. CGM and DG: performed data analysis, summarised results, critically reviewed the manuscript and approved the final manuscript as submitted. All authors approved the final manuscript as submitted and agree to be accountable for all aspects of the work.

Funding CoolCap study was supported by the Olympic Medical, Seattle, Washington, USA. No funding was received for this post hoc analysis. Role of the funder/sponsor: Olympic Medical supported the original CoolCap Study financially, provided administrative support to the sites, supplied the aEEG monitors and the cooling devices, and monitored initial data recording and accuracy, but had no input into the manuscript. The funding sources had no role in the analysis and interpretation of the data; preparation, review or approval of this manuscript; and decision to submit this manuscript for publication.

Competing interests None declared.

Patient consent Obtained.

Ethics approval The original CoolCap Study was approved by IRBs of each participating perinatal centres.

Provenance and peer review Not commissioned; externally peer reviewed.

Data sharing statement All original data are available with Dr Alistair Gunn and Steering Committee of the CoolCap Study.

\section{REFERENCES}

1 Hankins GDV, Speer M. Defining the pathogenesis and pathophysiology of neonatal encephalopathy and cerebral palsy. Obstet Gynecol 2003;102:628-36.
2 Kurinczuk JJ, White-Koning M, Badawi N. Epidemiology of neonatal encephalopathy and hypoxic-ischaemic encephalopathy. Early Human Dev 2010;86:329-38.

3 Jacobs SE, Berg M, Hunt R, et al. Cooling for newborns with hypoxic ischaemic encephalopathy. Cochrane Database Syst Rev 2013:1:CD003311.

4 Shankaran S, Laptook AR, Pappas A, et al. Effect of depth and duration of cooling on deaths in the NICU among neonates with hypoxic ischemic encephalopathy: a randomized clinical trial. JAMA 2014;312:2629-39.

5 Inder TE, Volpe JJ. Mechanisms of perinatal brain injury. Semin Neonatol 2000;5:3-16.

6 Jones MD Jr., Burd LI, Makowski EL, et al. Cerebral metabolism in sheep: A comparative study of the adult, the lamb, and the fetus. Am J Physiol 1975;229:235-9.

7 Nadeem M, Murray D, Boylan G, et al. Early blood glucose profile and neurodevelopmental outcome at two years in neonatal hypoxic-ischaemic encephalopathy. BMC Pediatr 2011;11:10.

8 Salhab WA, Wyckoff MH, Laptook AR, et al. Initial hypoglycemia and neonatal brain injury in term infants with severe fetal acidemia. Pediatrics 2004;114:361-6.

9 Basu P, Som S, Choudhuri N, et al. Contribution of the blood glucose level in perinatal asphyxia. Eur J Pediatr 2009;168:833-8

10 Spies EE, Lababidi SL, McBride MC. Early hyperglycemia is associated with poor gross motor outcome in asphyxiated term newborns. Pediatr Neurol 2014:50:586-90.

11 Park TS, Gonzales ER, Shah AR. Hypoglycemia selectively abolishes hypoxic reactivity of pial arterioles in piglets: role of adenosine. Am J Physiol 1995;268: H871-8.

12 McGowan J, Chen L, Gao D. Increased mitochondrial reactive oxygen species production in newborn brain during hypoglycemia. Neurosci Lett 2006;399:111-14

13 Auer RN. Hypoglycemic brain damage. Metab Brain Dis 2004;19:169-75.

14 Chang YS, Park WS, Ko SY, et al. Effects of fasting and insulin-induced hypoglycemia on brain cell membrane function and energy metabolism during hypoxia-ischemia in newborn piglets. Brain Res 1999;844:135-42.

15 LeBlanc MH, Huang M, Vig V, et al. Glucose affects the severity of hypoxic-ischemic brain injury in newborn pigs. Stroke 1993;24:1055-62.

16 Petersson $\mathrm{KH}$, Pinar $\mathrm{H}$, Stopa EG, et al. Effects of exogenous glucose on brain ischemia in ovine fetuses. Pediatr Res 2004:56:621-9.

17 Lin B, Ginsberg MD, Busto R. Hyperglycemic exacerbation of neuronal damage following forebrain ischemia: microglial, astrocytic and endothelial alterations. Acta Neuropathol 1998;96:610-20.

18 Gluckman PD, Wyatt JS, Azzopardi D, et al. Selective head cooling with mild systemic hypothermia after neonatal encephalopathy: multicentre randomised trial. Lancet 2005;365:663-70.

19 Sarnat HB, Sarnat MS. Neonatal encephalopathy following fetal distress. A clinical and electroencephalographic study. Arch Neurol 1976;33:696-705.

20 Randall GC. Studies on the effect of acute asphyxia on the fetal pig in utero. Biol Neonate 1979;36:63-9.

21 Jensen EC, Bennet L, Hunter $\mathrm{CJ}$, et al. Post-hypoxic hypoperfusion is associated with suppression of cerebral metabolism and increased tissue oxygenation in near-term fetal sheep. I Physiol 2006:572(Pt 1):131-9.

22 Davidson JO, Fraser M, Naylor AS, et al. Effect of cerebral hypothermia on cortisol and adrenocorticotropic hormone responses after umbilical cord occlusion in preterm fetal sheep. Pediatr Res 2008;63:51-5.

23 Hays $\mathrm{S}$, Smith E, Sunehag A. Hyperglycemia is a risk factor for early death and morbidity in extremely low birth-weight infants. Pediatrics 2006;118:1811-18.

24 Mitanchez-Mokhtari D, Lahlou N, Kieffer F, et al. Both relative insulin resistance and defective islet beta-cell processing of proinsulin are responsible for transient hyperglycemia in extremely preterm infants. Pediatrics 2004;113(3 Pt 1): 537-41.

25 Sunehag A, Gustafsson J, Ewald U. Very immature infants ( $<0 r=30 \mathrm{Wk}$ ) respond to glucose infusion with incomplete suppression of glucose production. Pediatr Res 1994;36:550-5.

26 Cornblath M. Neonatal hypoglycemia 30 years later: does it injure the brain? Historical summary and present challenges. Acta Paediatr Jpn 1997;39:S7-S11.

27 Boluyt N, van Kempen A, Offringa M. Neurodevelopment after neonatal hypoglycemia: a systematic review and design of an optimal future study. Pediatrics 2007;117:2231-44.

28 Kaiser JR, Bai S, Gibson N, et al. Association between transient newborn hypoglycemia and fourth-grade achievement test proficiency: a population-based study. JAMA Pediatr in press.

29 Adamkin DH, Committee on Fetus and Newborn. Postnatal glucose homeostasis in late-preterm and term infants. Pediatrics 2011;127:575-9.

30 Tam EWY, Haeusslein LA, Bonifacio SL, et al. Hypoglycemia is associated with increased risk for brain injury and adverse neurodevelopmental outcome in neonates at risk for encephalopathy. J Pediatr 2012;161:88-93.

31 Vannucci RC, Nardis EE, Vannucci SJ, et al. Cerebral carbohydrate and energy metabolism during hypoglycemia in newborn dogs. Am J Physiol 1981;240: R192-9.

32 Blomstrand S, Hrbek A, Karlsson K. Does glucose administration affect the cerebral response to fetal asphyxia? Acta Obstet Gynecol Scand 1984;63:345-53. 
33 LeBlanc $M H$, Huang $M$, Patel $D$, et al. Glucose given after hypoxic ischemia does not affect brain injury in piglets. Stroke 1994;25:1443-7.

34 Sheldon RA, Partridge JC, Ferriero DM. Postischemic hyperglycemia is not protective to the neonatal rat brain. Pediatr Res 1992;32:489-93.

35 Park W, Chang Y, Lee M. Effects of hyperglycemia or hypoglycemia on brain cell membrane function and energy metabolism during the immediate reoxygenation-reperfusion period after acute transient global hypoxia-ischemia in the newborn piglet. Brain Res 2001:901:102-8.

36 Koome ME, Davidson JO, Drury PP, et al. Antenatal dexamethasone after asphyxia increases neural injury in preterm fetal sheep. PLOS ONE 2013;8:e77480.
37 Katz LM, Wang Y, Ebmeyer U, et al. Glucose plus insulin infusion improves cerebral outcome after asphyxial cardiac arrest. Neuroreport 1998;9:3363-7.

38 Shi Y, Zhao J-N, Liu L, et al. Changes of positron emission tomography in newborn infants at different gestational ages, and neonatal hypoxic-ischemic encephalopathy. Pediatr Neurol 2012;46:116-23.

39 Thorngren-Jerneck K, Ohlsson T, Sandell A, et al. Cerebral glucose metabolism measured by positron emission tomography in term newborn infants with hypoxic ischemic encephalopathy. Pediatr Res 2001;49:495-501.

40 Wong DST, Poskitt KJ, Chau V, et al. Brain injury patterns in hypoglycemia in neonatal encephalopathy. Am J Neuroradiol 2013;34:1456-61. 